\title{
Safety margin of embolized area can reduce local recurrence of hepatocellular carcinoma after superselective transarterial chemoembolization
}

\author{
Kittipitch Bannangkoon', Keerati Hongsakul', Teeravut Tubtawee' ${ }^{1}$ and Teerha Piratvisuth ${ }^{2}$ \\ 'Department of Radiology, Faculty of Medicine, Prince of Songkla University, Songkhla; ${ }^{2}$ NKC Institute of Gastroenterology and Hepa- \\ tology, Faculty of Medicine, Prince of Songkla University, Songkhla, Thailand
}

Background/Aims: We aimed to determine the relationship between the safety margin of an embolized area and local tumor recurrence (LTR) of patients with hepatocellular carcinoma (HCC) who underwent superselective transarterial chemoembolization (TACE).

Methods: The medical records of $77 \mathrm{HCC}$ patients with $109 \mathrm{HCC}$ nodules who underwent superselective TACE were retrospectively analyzed for LTR. Univariate and multivariate analyses were performed for 16 potential factors using Cox proportional hazard regression. lodized oil deposition on cone-beam computed tomography (CBCT) imaging was divided into three grades: $A=$ complete tumor staining and complete circumferential safety margin, $B=$ complete tumor staining but incomplete safety margin, $C=$ =incomplete tumor staining. The effect of a safety margin on LTR was evaluated by comparison between grade $A$ and $B$ group.

Results: Univariate and multivariate analyses revealed that grade $A$ iodized oil deposition and portal vein visualization were the only two independent significant factors of LTR $(P<0.001$ and $P=0.029$, respectively). The 12- and 24-month LTR rates of tumors for grade $A(n=62)$, grade $B(n=30)$, and grade $C(n=17)$ were $16 \%$ vs. $41 \%$ vs. $100 \%$ and $16 \%$ vs. $61 \%$ vs. $100 \%$, respectively $(P<0.001)$. The tumors in the grade $A$ group had a $75 \%$ risk reduction in LTR (odds ratio, $0.25 ; 95 \%$ confidence interval, 0.10 to $0.64 ; P=0.004$ ) compared to the grade $B$ group.

Conclusions: LTR was significantly lower when a greater degree of iodized oil deposition occurred with a complete circumferential safety margin. In superselective TACE, the safety margin of the embolized areas using intraprocedural CBCT affected LTR in HCC patients. (Clin Mol Hepatol 2019;25:74-85)

Keywords: Hepatocellular carcinoma; Therapeutic embolization; Cone-beam computed tomography; Local neoplasm recurrence; Surgical margins

\footnotetext{
Study Highlights

Local tumor recurrence was significantly lower when treatment had a greater degree of iodized oil deposition with a safety margin. In superselective transarterial chemoembolization, the safety margin of the embolized areas using intraprocedural cone-beam computed tomography affected local tumor recurrence in hepatocellular carcinoma patients.
}

\section{Abbreviations:}

AFP, alpha-fetoprotein; CBCT, cone-beam computed tomography; Cl, confidence interval; HCC, hepatocellular carcinoma; LTR, local tumor recurrence; OR, odds ratio; RFA, radiofrequency ablation; TACE, transarterial chemoembolization

\section{Corresponding author : Kittipitch Bannangkoon}

Department of Radiology, Faculty of Medicine, Prince of Songkla University, 15 Kanchanavanit Road, Hat Yai, Songkhla 90110, Thailand

Tel: +66-74-451517, Fax: +66-74-429927

E-mail: drkittipitch@gmail.com

https://orcid.org/0000-0003-1926-5239 


\section{INTRODUCTION}

Hepatocellular carcinoma (HCC) is a common malignancy worldwide and the second leading cause of tumor-related death after lung cancer. ${ }^{1}$ Surgical resection and liver transplantation are considered as curative treatments for HCC patients who are good surgical candidates. ${ }^{2,3}$ Unfortunately, the majority of HCC patients can not have resection performed due to multifocal disease, portal hypertension or poor hepatic functional reserve. Transarterial chemoembolization (TACE) is one of the effective treatments in patients with unresectable $\mathrm{HCC}^{4-9}$ However, the local tumor recurrence (LTR) rate of HCC patients who have undergone TACE is normally higher than radiofrequency ablation (RFA) which removes the tumor and the parenchymal tissues that surround the tumor nodule. ${ }^{10,11}$ As with RFA, chemoembolization of liver parenchyma around the tumor nodule in superselective TACE may reduce LTR.

Recently, cone-beam computed tomography (CBCT) is used to detect the tumors, tumor feeding arteries and to monitor the embolized area during TACE. ${ }^{12-15}$ However, efficacy of the safety margin using intraprocedural CBCT for local tumor control is still uncertain in superselective TACE in HCC patients. Therefore, the purpose of this study was to determine the relationship between the safety margin of the embolized area and LTR following TACE with intraprocedural monitoring with CBCT.

\section{MATERIALS AND METHODS}

We performed a retrospective study to determine the relationship between LTR and the safety margin of an embolized area defined as completely surrounding an HCC nodule with parenchymal iodized oil accumulation on CBCT images immediately after superselective TACE. Approval to conduct this study was obtained from the institutional ethics committee (61-170-7-1).

\section{Patient population}

Between November 2015 and December 2017, 776 TACE procedures were performed in 375 patients with HCC at our hospital. For this study we selected patients who met the following inclusion criteria: (a) patients with unresectable HCC with liver cirrhosis; (b) had tumor size $\leq 7 \mathrm{~cm}$ in diameter and the number of distinct tumor nodules $\leq 5$; (c) patients treated with superselective TACE with catheterization at the subsegmental hepatic artery feeding the tumor; (d) had tumors treated with TACE alone; and (e) available CBCT images taken immediately after superselective TACE. The excluded patients were those with severe impaired hepatic function (Child-Pugh class C), extrahepatic metastasis, infiltrative tumors, and severe arterioportal shunt.

We followed the American Association for the Study of Liver Diseases criteria for the diagnosis of $\mathrm{HCC}^{16}$ Liver nodules larger than $1 \mathrm{~cm}$ in diameter were evaluated by dynamic magnetic resonance imaging or multidetector computed tomography scan using contrast media. If the imaging appearance was typical of HCC, no further diagnostic procedure was attempted.

All patients underwent blood investigations including complete blood count, liver function test, coagulation test, viral markers for hepatitis B and C infection, and serum alpha-fetoprotein (AFP). The assessment of chronic liver disease was based on the ChildPugh classification system.

Following the inclusion criteria, 77 patients (48 male, 29 female) were selected for our study. The mean age was $63.2 \pm 9.6$ years (range, 41-81 years). All patients had liver cirrhosis, which was related with hepatitis B in 46 patients $(60 \%)$, hepatitis C in 14 patients (18\%), and alcohol abuse in 6 patients (8\%). The numbers of patients with Child Pugh classes $A$ and $B$ were 63 $(82 \%)$ and $14(18 \%)$, respectively. Fifty-seven patients (74\%) had AFP level $\leq 200 \mathrm{ng} / \mathrm{mL}$. A solitary nodule was present in 66 (79\%) patients and multiple nodules in 17 (21\%) patients. In 83 sessions of TACE, a total of 109 HCC nodules were obtained with a mean diameter of $26.4 \pm 14.6 \mathrm{~mm}$ (range, 10-69 mm). Demographic and procedural data of the 77 patients are summarized in Table 1.

\section{Superelective TACE steps and technique}

All eligible HCC patients underwent superselective conventional TACE, defined as catheterization at the subsegmental hepatic artery performed by two interventional radiologists through the transfemoral route. Superior mesenteric artery and celiac axis arteriogram were selective at the beginning of the procedure using a 5-Fr selective catheter (Cobra, Chuang or MIK catheter; Boston Scientific, Limerick, Ireland) and a 0.035-inch J-tip Terumo guidewire. We performed selective catheterization to the tumor feeding hepatic arteries or in extrahepatic collaterals as distal as possible in each tumor lesion using a microcatheter, of either a 1.98-Fr tip Parkway Soft microcatheter from Asahi or a 2.0-Fr tip Progreat microcatheter from Terumo, over a 0.016-inch or a 0.018-inch guidewire. After the microcatheter was inserted into the target arterial feeder, $0.5-1.0 \mathrm{~mL}$ of $2 \%$ lidocaine (lidocaine hydrochlo- 
Table 1. Patient and tumor characteristics and procedural data at baseline

\begin{tabular}{|c|c|}
\hline Characteristics & Value \\
\hline Tumor (n) & 109 \\
\hline TACE sessions (n) & 83 \\
\hline Patients (n) & 77 \\
\hline $\begin{array}{l}\text { Sex }(n, \%) \\
\text { Male } \\
\text { Female }\end{array}$ & $\begin{array}{l}48(62) \\
29(38)\end{array}$ \\
\hline Age (years) & $63.2 \pm 9.6(41-81)$ \\
\hline $\begin{array}{l}\text { Etiology (n, \%) } \\
\text { Hepatitis B } \\
\text { Hepatitis C } \\
\text { Alcohol } \\
\text { Other }\end{array}$ & $\begin{array}{l}46(60) \\
14(18) \\
6(8) \\
11(14)\end{array}$ \\
\hline $\begin{array}{l}\text { Child-Pugh class (n, \%) } \\
\text { A } \\
\text { B }\end{array}$ & $\begin{array}{l}63(82) \\
14(18)\end{array}$ \\
\hline $\begin{array}{l}\text { AFP }(n g / m L)(n, \%) \\
\quad<10 \\
10-200 \\
>200\end{array}$ & $\begin{array}{l}27(35) \\
30(39) \\
20(26)\end{array}$ \\
\hline Total bilirubin (mg/dL) & $0.93 \pm 0.57(0.3-2.5)$ \\
\hline AST (U/L) & $57.8 \pm 46.3(18-266)$ \\
\hline $\operatorname{ALT}(\mathrm{U} / \mathrm{L})$ & $39.3 \pm 35.2(12-257)$ \\
\hline Prothrombin time (s) & $14.5 \pm 2.3(1-19)$ \\
\hline Albumin (ng/mL) & $3.6 \pm 0.5(2.4-4.7)$ \\
\hline $\begin{array}{l}\text { Portal hypertension }(\mathrm{n}, \%) \\
\text { Absent } \\
\text { Present }\end{array}$ & $\begin{array}{l}29(38) \\
48(62)\end{array}$ \\
\hline $\begin{array}{l}\text { Ascites (n, \%) } \\
\text { Absent } \\
\text { Present }\end{array}$ & $\begin{array}{r}68(88) \\
9(12)\end{array}$ \\
\hline Tumor size (mm) & $26.4 \pm 14.6(10-69)$ \\
\hline Tumor numbers (per sessions) & $1.3 \pm 0.7(1-4)$ \\
\hline $\begin{array}{l}\text { Tumor pattern (per sessions) (n } \\
\text { Single } \\
\text { Multiple nodules }(\leq 5)\end{array}$ & $\begin{array}{l}66(79) \\
17(21)\end{array}$ \\
\hline $\begin{array}{l}\text { Tumor location (n, \%) } \\
\text { Right lobe } \\
\text { Left lobe } \\
\text { Caudate lobe }\end{array}$ & $\begin{array}{l}90(82) \\
18(17) \\
1(1)\end{array}$ \\
\hline Dose of iodized oil (mL) & $6.2 \pm 3.0(2-16)$ \\
\hline Dose of doxorubicin (mg) & $17.5 \pm 8.4(5-50)$ \\
\hline $\begin{array}{l}\text { Tumor feeding artery }(n, \%) \\
\text { Hepatic artery } \\
\text { Extrahepatic artery }\end{array}$ & $\begin{array}{c}107(98) \\
2(2)\end{array}$ \\
\hline
\end{tabular}

Data are presented as mean \pm standard deviation (range) or $n(\%)$ unless indicated otherwise.

TACE, transarterial chemoembolization; AFP, alpha-fetoprotein; AST, aspartate transaminase; $\mathrm{ALT}$, alanine transaminase. ride, Government Pharmaceutical Organization, Bangkok, Thailand) was infused intra-arterially to prevent vasospasm and provide pain relief.

We slowly administered the mixture of iodized oil (range, 2-16 mL, Lipiodol, Guerbet) and doxorubicin hydrochloride (range 5-50 mg) (Adriamycin, Pfizer) under real time monitoring with digital subtraction angiography (Phillips AlluraClarity FD20). The amount of anticancer-in-oil-emulsion was determined by total tumor size and the number of nodules. We mixed 2-4 volumes of oil with one volume of aqueous drug to promote formulation of water in oil emulsion. Subsequently, the feeding artery was embolized using gelatin sponge particles. We completed the procedure when the tumor feeding branch was completely obstructed and tumor staining from digital subtraction angiography completely disappeared. CBCT was performed just after the superselective TACE procedure to evaluate the grade of the safety margin of the embolized area.

\section{CBCT technique}

The CBCT was operated using Allura Clarity FD20 (Philips Healthcare, Eindhoven, the Netherlands) with the XperCT option, enabling $\mathrm{CBCT}$ acquisition and volumetric image reconstruction. $\mathrm{A}$ total of 242 projection images (60 frames per second) with X-ray parameters of $121 \mathrm{kV}$ and 200-300 mAs were obtained with the motorized C-arm covering a $220^{\circ}$ clockwise rotation of the flat panel detectors. The patients were instructed to be at end-expiratory apnea during the CBCT scanning. All CBCT images of 5-mm thickness were interpreted using a work station (Phillips Healthcare).

\section{Analysis of the prognostic factors for LTR}

Univariate and multivariate analyses were used to determine the significant independent factors affecting LTR. Ten clinical factors were analyzed: gender, age, etiology of cirrhosis, Child-Pugh class, AFP, albumin, total bilirubin, prothrombin time, ascites, and portal hypertension. Also analyzed were two tumor factors (tumor size and location) and four procedure-related factors (iodized oil deposition with safety margin on CBCT images, portal vein visualization at spot digital radiography, dose of doxorubicin, and dose of iodized oil).

\section{Classification of iodized oil deposition with a safety margin}

lodized oil deposition with a safety margin of the embolized 
area using CBCT immediately after superselective TACE was divided into three grades (Fig. 1, 2).

Grade A means the entire tumor which was embolized and complete encasement of the tumor with parenchymal iodized oil deposition of any thickness (complete tumor staining and complete circumferential safety margin).

Grade B means the entire tumor which was embolized but not complete encasement of the tumor with parenchymal iodized oil deposition (complete tumor staining but incomplete circumferential safety margin), and was divided into two grades; grade B1 means incomplete encasement of the tumor by parenchymal iodized oil deposition; grade B2 means no encasement of the tumor by parenchymal iodized oil deposition.

Grade C means the entire tumor was not embolized (incomplete tumor staining) and was divided into two grades; grade C1 means defect of iodized oil uptake located periphery; grade C2 means defect of iodized oil uptake located centrally.

All CBCT images were retrospectively interpreted by two radiologists.

\section{Outcome and follow-up imaging study}

All patients were followed-up after superselective TACE with a detailed clinical examination, blood chemistry, and imaging examination (dynamic magnetic resonance imaging or 4-phase con- trast-enhanced computed tomography scan) one month after the initial procedure. If no definite evidence of residual tumor was shown, then imaging examination was performed at 3-4 month intervals thereafter. LTR was diagnosed when arterial enhancement was seen in or adjacent to the treated tumor on follow-up imaging. The decision to repeat the TACE procedure was based on tumor response, Barcelona Clinic Liver Cancer stage of the disease, and the patient's tolerance.

\section{Complications}

Superselective TACE-related complications were retrospectively reviewed with a physical examination, laboratory results, and follow-up imaging. The complications were classified as major or minor following the standard Society of Interventional Radiology guidelines. ${ }^{17}$

\section{Statistical analysis}

Data analyses were performed using Stata version 14.2 (Stata Corp, Texas, TX, USA). Numerical data are presented descriptively using the central tendency (mean, median, and mode) and a measure of dispersion (standard deviation and range).

A comparison of the clinical, tumor, and procedure-related factors were initially assessed with univariate analysis. Subsequently,

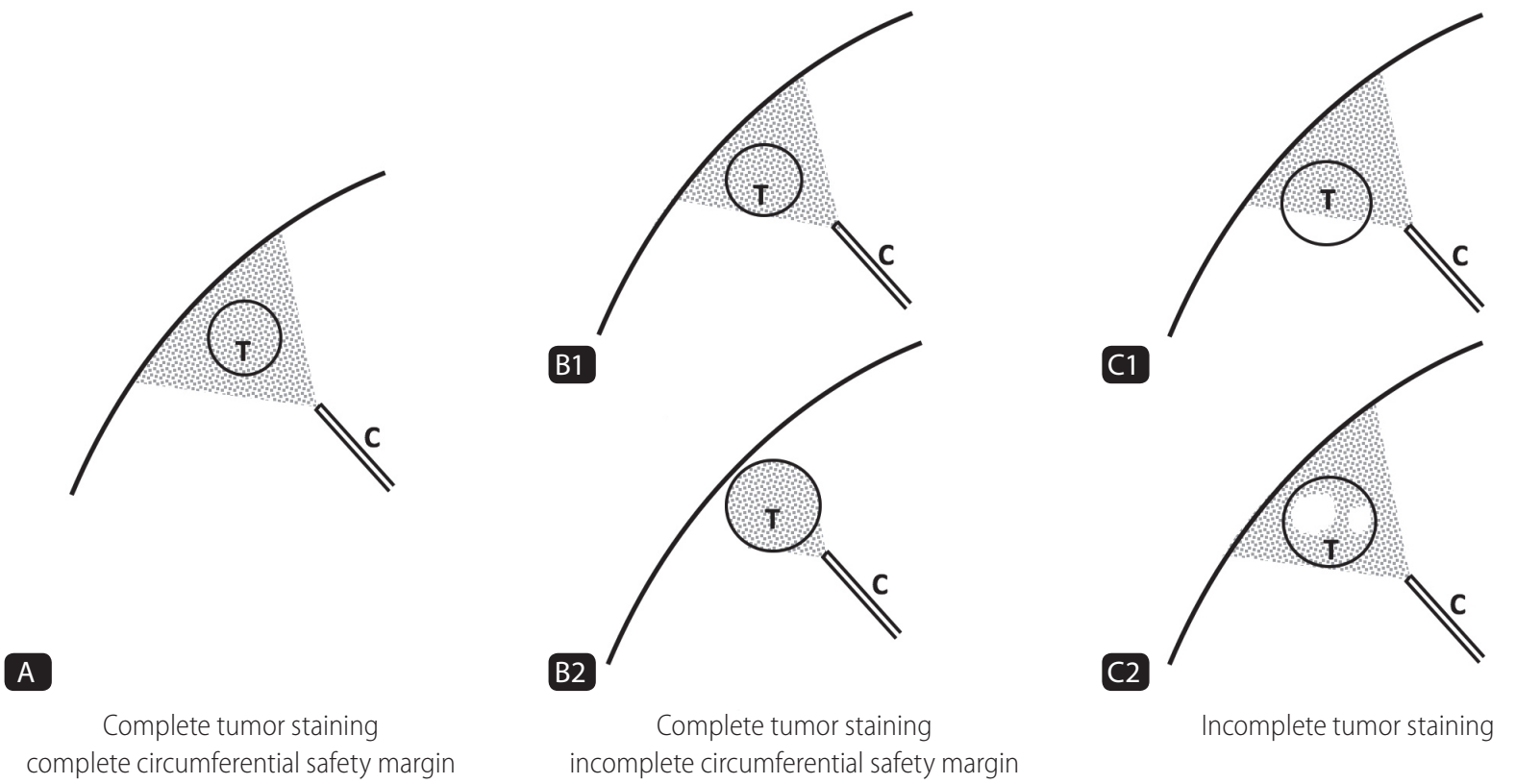

Figure 1. Schematic representation of the grade of iodized oil deposition with safety margin. Gray colored area: area of iodized oil deposition. White colored area: defect area of iodized oil uptake. T, tumor; C, catheter. 


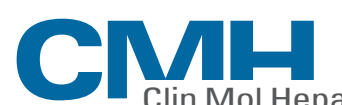

Volume 25 Number_1 March 2019
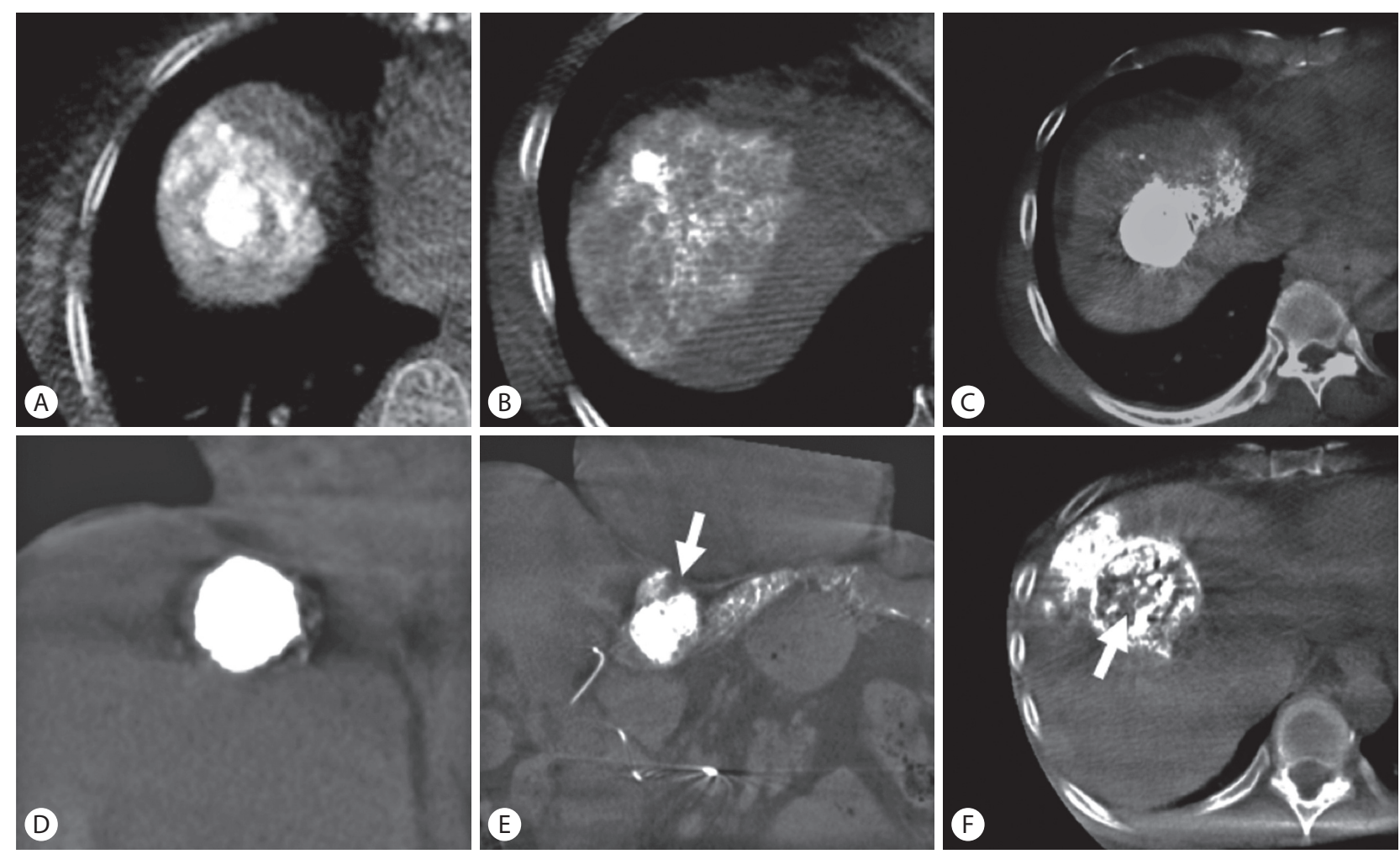

Figure 2. Methods used to determine grade of iodized oil deposition and safety margin on cone-beam computed tomography images. (A, B) Grade A: entire tumor was embolized with complete encasement of the tumor by parenchymal iodized oil deposition. (C) Grade B1: entire tumor was embolized with incomplete encasement of the tumor by parenchymal iodized oil deposition. (D) Grade B2: entire tumor was embolized with no encasement by parenchymal iodized oil deposition. (E) Grade C1: defect of iodized oil uptake at the periphery of the tumor (arrow). (F) Grade C2: defect of iodized oil uptake in the central tumor (arrow).

all factors having a $P$-value $\leq 0.2$ from the univariate analysis were entered into the initial multivariate Cox proportional hazard regression, and the model refined by sequentially removing non-significant variables. $P$-values less than 0.05 were considered indicative of a statistically significance.

The purpose of our study was to determine the relationship between the safety margin of the embolized area and LTR in superselective TACE. Therefore, the LTR rates were compared between group $A$ and group $B$ based on the $C B C T$ images. The probability of LTR was estimated using the Kaplan-Meier method. The overall LTR rates at 6, 12, and 24 months were calculated and compared for each group.

\section{RESULTS}

\section{TACE procedures}

Intrahepatic arteries were embolized in 107 nodules and extra- hepatic arteries were embolized in 2 nodules via inferior phrenic arteries. The mean dose of iodized oil in one session of TACE was about $6.2 \pm 3.0 \mathrm{~mL}$ (range, 2-16 mL) and the mean dose of doxorubicin in one session of TACE was about $17.5 \pm 8.4 \mathrm{mg}$ (range, 5-50 mg).

\section{Prognostic factors of LTR}

Among the 16 prognostic factors affecting LTR, univariate analysis revealed that a lower serum AFP level $(\leq 200 \mathrm{ng} / \mathrm{mL})$ was the only significant clinical factor $(P=0.010)$. Of the two tumor factors, tumor size less than $30 \mathrm{~mm}$ was a significant tumor factor on univariate analysis $(P=0.045)$. In addition, the grade of iodized oil deposition with a safety margin and portal vein visualization were significant procedure-related factors $(P<0.001$ and $P=0.023)$ (Table 2).

Multivariate analysis for the potential prognostic factors affecting LTR on the univariate analysis showed that the grade of iodized oil deposition with a safety margin and portal vein visualiza- 
Kittipitch Bannangkoon, et al. Safety margin can reduce local recurrence of HCC after TACE

Table 2. Comparison of prognostic factors and results of univariate analysis among hepatocellular carcinoma patients with local tumor recurrence underwent superselective transarterial chemoembolization compared to those who did not

\begin{tabular}{|c|c|c|c|c|}
\hline Factors & No recurrence $(n=75)$ & Recurrence ( $n=34)$ & $\begin{array}{c}\text { Odds ratio } \\
(95 \% \mathrm{Cl})\end{array}$ & $P$-value \\
\hline \multicolumn{5}{|l|}{ Clinical factors } \\
\hline $\begin{array}{l}\text { Gender } \\
\text { Male } \\
\text { Female }\end{array}$ & $\begin{array}{l}46(61) \\
29(39)\end{array}$ & $\begin{array}{l}24(71) \\
10(29)\end{array}$ & $\begin{array}{l}1 \\
0.63(0.30-1.32)\end{array}$ & 0.207 \\
\hline $\begin{array}{l}\text { Age (years) } \\
\leq 60 \\
>60\end{array}$ & $\begin{array}{l}28(37) \\
47(63)\end{array}$ & $\begin{array}{l}15(44) \\
19(56)\end{array}$ & $\begin{array}{c}1 \\
0.68(0.34-1.34)\end{array}$ & 0.268 \\
\hline $\begin{array}{l}\text { Etiology } \\
\text { HBV } \\
\text { HCV } \\
\text { Alcohol } \\
\text { Other }\end{array}$ & $\begin{array}{l}47(63) \\
14(19) \\
6(8) \\
8(10)\end{array}$ & $\begin{array}{l}17(50) \\
7(21) \\
3(9) \\
7(20)\end{array}$ & $\begin{array}{l}0.54(0.22-1.31) \\
0.77(0.27-2.21) \\
0.69(0.18-2.68) \\
\quad 1\end{array}$ & 0.581 \\
\hline $\begin{array}{l}\text { Child-Pugh Class } \\
\text { A } \\
\text { B }\end{array}$ & $\begin{array}{l}59(79) \\
16(21)\end{array}$ & $\begin{array}{r}26(77) \\
8(23)\end{array}$ & $\begin{array}{l}0.79(0.36-1.76) \\
\quad 1\end{array}$ & 0.575 \\
\hline $\begin{array}{l}\text { Alpha fetoprotein }(\mathrm{ng} / \mathrm{mL}) \\
\leq 200 \\
>200\end{array}$ & $\begin{array}{l}56(75) \\
19(25)\end{array}$ & $\begin{array}{l}20(59) \\
14(41)\end{array}$ & $\begin{array}{l}0.39(0.19-0.78) \\
1\end{array}$ & $0.010^{*}$ \\
\hline $\begin{array}{l}\text { Albumin }(\mathrm{ng} / \mathrm{mL}) \\
\leq 3.5 \\
>3.5\end{array}$ & $\begin{array}{l}34(45) \\
41(55)\end{array}$ & $\begin{array}{l}15(44) \\
19(56)\end{array}$ & $\begin{array}{l}1 \\
0.86(0.44-1.70)\end{array}$ & 0.668 \\
\hline $\begin{array}{l}\text { Total bilirubin }(\mathrm{mg} / \mathrm{dL}) \\
\leq 1.5 \\
>1.5\end{array}$ & $\begin{array}{c}68(91) \\
7(9)\end{array}$ & $\begin{array}{r}27(79) \\
7(21)\end{array}$ & $\begin{array}{l}0.43(0.19-0.99) \\
\quad 1\end{array}$ & 0.068 \\
\hline $\begin{array}{l}\text { Prothrombin time (s) } \\
\leq 13.5 \\
>13.5\end{array}$ & $\begin{array}{l}25(33) \\
50(67)\end{array}$ & $\begin{array}{l}10(29) \\
24(71)\end{array}$ & $\begin{array}{l}0.77(0.37-1.61) \\
1\end{array}$ & 0.483 \\
\hline $\begin{array}{l}\text { Ascites } \\
\text { No } \\
\text { Yes }\end{array}$ & $\begin{array}{c}68(91) \\
7(9)\end{array}$ & $\begin{array}{r}28(82) \\
6(18)\end{array}$ & $\begin{array}{l}0.60(0.25-1.46) \\
\quad 1\end{array}$ & 0.287 \\
\hline $\begin{array}{l}\text { Portal hypertension } \\
\text { No } \\
\text { Yes }\end{array}$ & $\begin{array}{l}30(40) \\
45(60)\end{array}$ & $\begin{array}{r}9(26) \\
25(74)\end{array}$ & $\begin{array}{l}0.60(0.28-1.29) \\
\quad 1\end{array}$ & 0.179 \\
\hline \multicolumn{5}{|l|}{ Tumor factors } \\
\hline $\begin{array}{l}\text { Tumor size } \\
\leq 30 \mathrm{~mm} \\
>30 \mathrm{~mm}\end{array}$ & $\begin{array}{l}57(76) \\
18(24)\end{array}$ & $\begin{array}{l}21(62) \\
13(38)\end{array}$ & $\begin{array}{l}0.47(0.23-0.96) \\
\quad 1\end{array}$ & $0.045^{*}$ \\
\hline $\begin{array}{l}\text { Tumor's location } \\
\text { Right lobe } \\
\text { Left lobe } \\
\text { Caudate lobe }\end{array}$ & $\begin{array}{c}64(85) \\
10(13) \\
1(1)\end{array}$ & $\begin{array}{l}26(77) \\
8(23) \\
0(0)\end{array}$ & $\begin{array}{l}0.57(0.26-1.27) \\
\quad 1 \\
-\end{array}$ & 0.275 \\
\hline \multicolumn{5}{|l|}{ Procedure-related factors } \\
\hline $\begin{array}{l}\text { lodized oil deposition with safety margin } \\
\text { Grade A } \\
\text { Grade B } \\
\text { Grade C }\end{array}$ & $\begin{array}{l}55(73) \\
17(23) \\
3(4)\end{array}$ & $\begin{array}{r}7(21) \\
13(38) \\
14(41)\end{array}$ & $\begin{array}{l}0.05(0.02-0.12) \\
0.19(0.08-0.42) \\
\quad 1\end{array}$ & $<0.001^{*}$ \\
\hline
\end{tabular}


Table 2. Continued

\begin{tabular}{|c|c|c|c|c|}
\hline Factors & No recurrence $(n=75)$ & Recurrence $(n=34)$ & $\begin{array}{l}\text { Odds ratio } \\
(95 \% \mathrm{Cl})\end{array}$ & $P$-value \\
\hline $\begin{array}{l}\text { Portal vein visualization } \\
\text { Prominent } \\
\text { Mild } \\
\text { No }\end{array}$ & $\begin{array}{r}34(45) \\
32(43) \\
9(12)\end{array}$ & $\begin{array}{r}8(24) \\
14(41) \\
12(35)\end{array}$ & $\begin{array}{l}0.29(0.12-0.71) \\
0.49(0.23-1.07) \\
\quad 1\end{array}$ & $0.023^{*}$ \\
\hline $\begin{array}{l}\text { Dose of doxorubicin } \\
\leq 20 \mathrm{mg} \\
>20 \mathrm{mg}\end{array}$ & $\begin{array}{l}60(80) \\
15(20)\end{array}$ & $\begin{array}{l}23(68) \\
11(32)\end{array}$ & $\begin{array}{l}0.48(0.24-1.00) \\
\quad 1\end{array}$ & 0.061 \\
\hline $\begin{array}{l}\text { Dose of Lipiodol } \\
\leq 8 \mathrm{~mL} \\
>8 \mathrm{~mL}\end{array}$ & $\begin{array}{l}61(81) \\
14(19)\end{array}$ & $\begin{array}{l}24(71) \\
10(29)\end{array}$ & $\begin{array}{l}0.49(0.23-1.03) \\
1\end{array}$ & 0.073 \\
\hline
\end{tabular}

Data are presented as $n(\%)$ unless otherwise indicated.

$\mathrm{Cl}$, confidence interval; HBV, hepatitis B virus; $\mathrm{HCV}$, hepatitis c virus.

*Likelihood ratio test.

Table 3. Results of univariate and multivariate analyses on potential prognostic factors affecting local tumor recurrence after superselective transarterial chemoembolization

\begin{tabular}{|c|c|c|c|c|}
\hline \multirow{2}{*}{ Factors } & \multicolumn{2}{|c|}{ Univariate } & \multicolumn{2}{|c|}{ Multivariate } \\
\hline & OR $(95 \% \mathrm{Cl})$ & $P$-value & OR $(95 \% \mathrm{Cl})$ & $P$-value \\
\hline Alpha fetoprotein ( $\leq 200 \mathrm{vs.}>200 \mathrm{ng} / \mathrm{mL}$ ) & $0.39(0.19-0.78)$ & $0.010^{*}$ & & \\
\hline Total bilirubin ( $\leq 1.5$ vs. $>1.5$ mg/dL) & $0.43(0.19-0.99)$ & 0.068 & & \\
\hline Portal hypertension (No vs. Yes) & $0.60(0.28-1.29)$ & 0.179 & & \\
\hline Tumor size ( $\leq 30$ vs. $>30$ mm) & $0.47(0.23-0.96)$ & $0.045^{*}$ & & \\
\hline lodized oil deposition with SM (gr A vs. B/C) & $0.15(0.06-0.34)$ & $<0.001^{*}$ & $0.16(0.07-0.39)$ & $<0.001^{*}$ \\
\hline PV visualization (Prominent/mild vs. None) & $0.39(0.19-0.79)$ & $0.014^{*}$ & $0.40(0.18-0.88)$ & $0.029^{*}$ \\
\hline Dose of doxorubicin ( $\leq 20 \mathrm{vs} .>20 \mathrm{mg}$ ) & $0.48(0.24-1.00)$ & 0.061 & & \\
\hline Dose of lipiodol ( $\leq 8 \mathrm{vs} .>8 \mathrm{~mL}$ ) & $0.49(0.23-1.03)$ & 0.073 & & \\
\hline
\end{tabular}

$\mathrm{OR}$, odds ratio; $\mathrm{Cl}$, confidence interval; $\mathrm{SM}$, safety margin; gr, grade; $\mathrm{PV}$, portal vein.

*Likelihood ratio test.

tion were the only two independently significant prognostic factors of $\operatorname{LTR}(P<0.001$ and $P=0.029)$ (Table 3).

In a subgroup analysis of 92 nodules with complete tumor staining (grade A and B group), a complete safety margin on CBCT images in grade $A$ group nodules remained a significant contributor to lower LTR rates (odds ratio [OR], 0.25 ; $95 \%$ confidence interval $[\mathrm{CI}], 0.10$ to $0.64 ; P=0.004$ ) than for tumors in the grade B group.

\section{Relationship between LTR and grade of iodized oil deposition with a safety margin}

The mean follow-up time for each HCC nodule was $14.4 \pm 6.8$ months (range, 3.8 to 30.9 months). Cumulative overall LTR rates were $25.3 \%(95 \% \mathrm{Cl}, 18.0$ to $35.0 \%)$ at 6 months, 35.6\% (95\% $\mathrm{Cl}, 26.0$ to $47.5 \%)$ at 12 months, and $44.6 \%(95 \% \mathrm{Cl}, 31.1$ to $60.8 \%)$ at 24 months. Of the 109 nodules, $62(56.9 \%)$ had grade A, $30(27.5 \%)$ had grade B, and 17 (15.6\%) had grade C (Table 4). Of the 62 tumors in the grade A group, 55 (89\%) had not recurred in $13.8 \pm 6.7$ months (range, 4.7 to 30.9 months) after superselective TACE (Fig. 3). Only seven tumors (11\%) recurred after 4.7 2.7 months (range, 1.0 to 7.5 months). Intratumoral recurrence was seen in 6 nodules (86\%) and peritumoral recurrence developed in one. Of the 30 tumors in the grade B group, 17 (57\%) had not recurred in $16.1 \pm 6.7$ months (range, 5.6 to 30.7 months) after superselective TACE. Thirteen tumors (43\%) recurred after 5.2 \pm 5.1 months (range, 1.0 to 16.6 months) (Fig. 4, 5). In the B1 group, peritumoral recurrence was noted in 9 nodules 
Table 4. Grades of iodized oil deposition and local tumor recurrence

\begin{tabular}{lccc}
\hline Grade of iodized oil deposition & Number & Local tumor recurrence & $\begin{array}{c}\text { Location of recurrence } \\
\text { (Peritumoral vs. Intratumoral) }\end{array}$ \\
\hline Grade A & $62(56.9)$ & $7(11.3)$ & 1 vs. 6 \\
\hline Grade B & $30(27.5)$ & $13(43.3)$ & 9 vs. 3 \\
B1 & 28 & 12 & 1 vs. 0 \\
B2 & 2 & 1 & $14(82.4)$ \\
Grade C & $17(15.6)$ & 9 & 0 vs. 9 \\
C1 & 9 & 5 & 0 vs. 5 \\
C2 & 8 & $34(31.2)$ & 11 vs. 23 \\
\hline Total & 109 & & \\
\hline
\end{tabular}

Data are presented as $n$ or $n(\%)$ unless otherwise indicated.
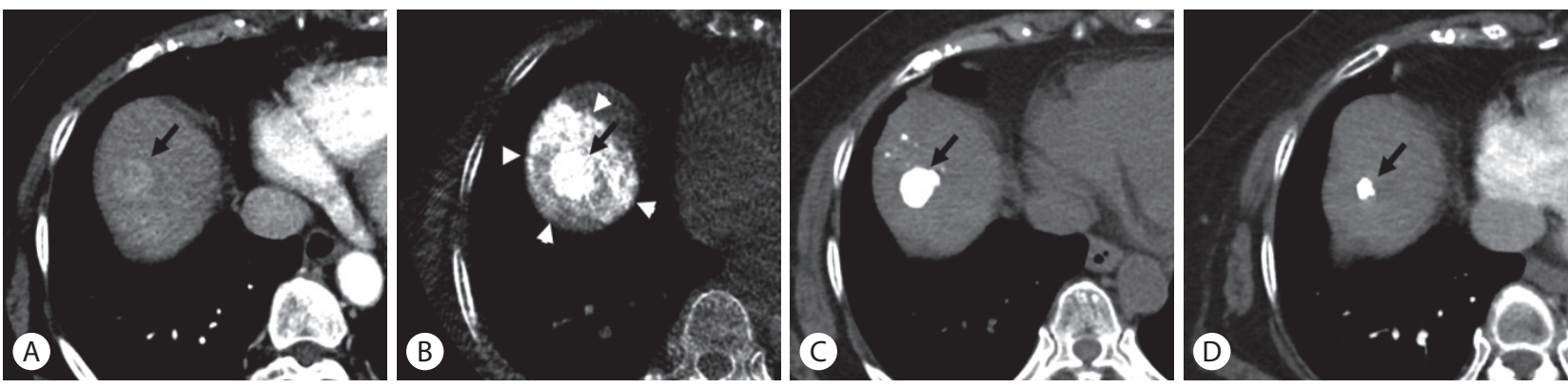

Figure 3. Sustained complete response after superselective transarterial chemoembolization (TACE) in a 73-year-old woman with hepatocellular carcinoma. (A) Enhanced computed tomography (CT) scan shows a 2.1-cm-sized hypervascular nodule at segment 8 of the right hepatic lobe (arrow). (B) Cone-beam CT scan obtained immediately after TACE shows dense iodized oil accumulation in the tumor (arrow) and complete encasement with parenchymal iodized oil deposition (arrowheads), which was classified as grade A. (C) Unenhanced CT scan obtained 1 month after TACE shows dense iodized oil accumulation in the tumor (arrow). (D) Enhanced CT scan obtained 22 months later; the treated nodule was decreased in size without evidence of local tumor recurrence (arrow).

(75\%) and intratumoral recurrence developed in three. One case in the B2 group recurred in the peritumoral region.

Of the 17 tumors in the grade C group, $3(18 \%)$ had not recurred in 5.9 2.9 months (range, 3.8 to 9.2 months) after superselective TACE. Fourteen tumors (82\%) recurred after $2.4 \pm 2.4$ months (range, 1.0 to 7.8 months). All cases in $\mathrm{C} 1$ and $\mathrm{C} 2$ groups recurred in the intratumoral region.

The cumulative 6-, 12-, and 24-month LTR rates of tumors for grade $A$, grade $B$, and grade $C$ were $7 \%$ vs. $35 \%$ vs. $81 \%, 16 \%$ vs. $41 \%$ vs. $100 \%$, and $16 \%$ vs. $61 \%$ vs. $100 \%$, respectively. The LTR rates for tumors in the grade A group were significantly lower than those for tumors in the grade $B$ and $C$ groups ( $P=0.004$ and $P<0.001$, respectively) (Fig. 6$)$. The LTR rates for tumors in the grade $B$ group were also significantly lower than in the grade $C$ group $(P<0.001)$.

\section{Complications}

None of the patients developed a major complication after superselective TACE. All treatment-related adverse toxicities were classified as minor. Post embolization syndrome (fever, abdominal pain, and increased white blood cell count) developed in $7 \mathrm{pa}$ tients (6.4\%) without requiring extended stay or re-admission. Groin hematoma occurred in 2 patients (1.8\%) but they were followed up without any treatment due to no symptoms.

\section{DISCUSSION}

TACE is one of the effective treatments in patients with unresectable HCC. ${ }^{4-9}$ Embolization with chemotherapeutic drugs, iodized oil, or embolic material in TACE leads to ischemic necrosis of the tumor tissue. ${ }^{18}$ Subsegmental (or superselective) TACE using a small microcatheter offers the advantages of targeted delivery to 

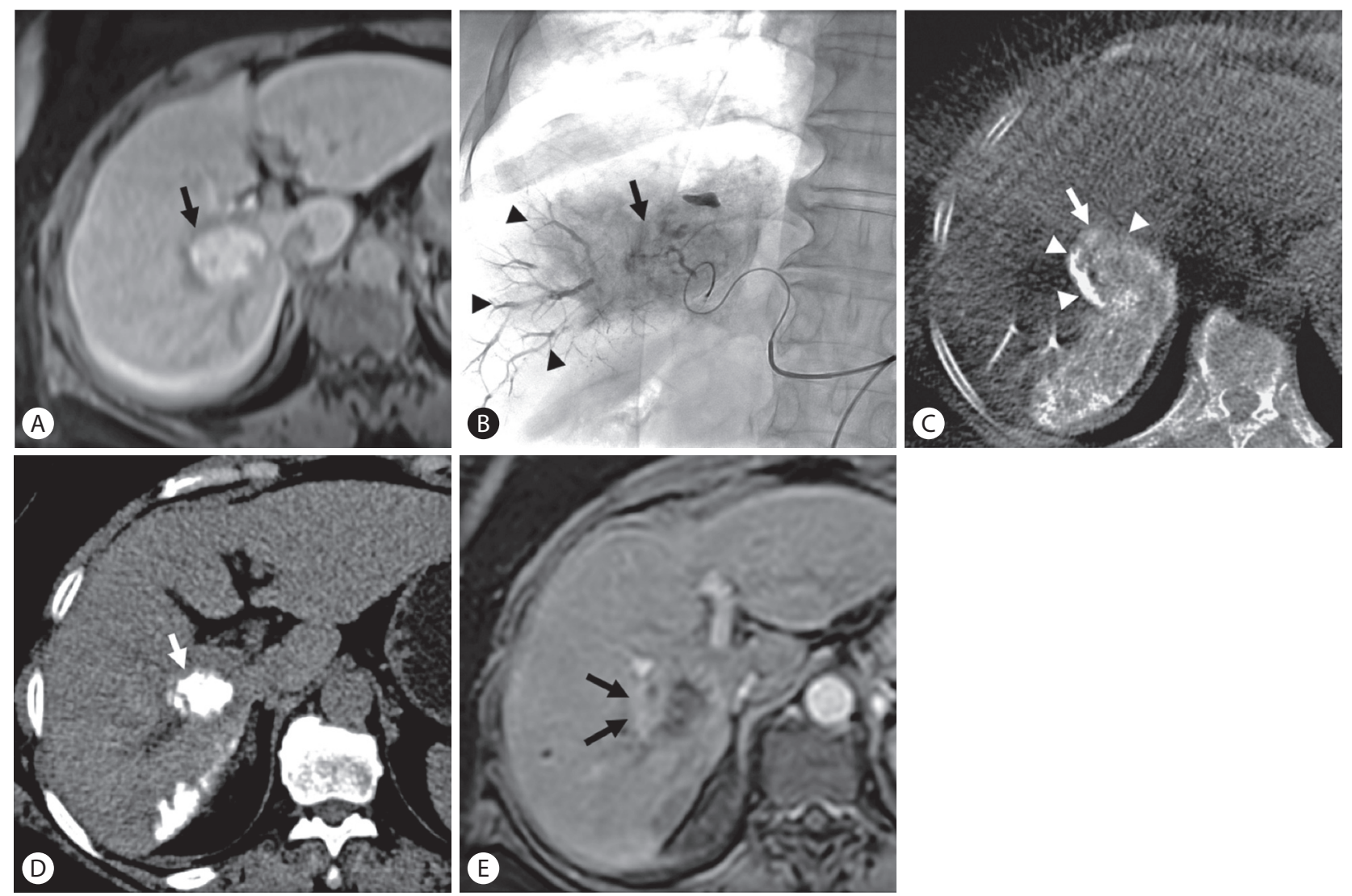

Figure 4. Local tumor recurrence after transarterial chemoembolization (TACE) in a 63-year-old woman with hepatocellular carcinoma. (A) Enhanced magnetic resonance (MR) images show a 3.5-cm-sized hypervascular tumor at segment 6 of the right hepatic lobe (arrow). (B) Spot radiograph obtained after TACE shows a tumor stain (arrow) with prominent portal veins in the embolized area (arrowheads). (C) Cone-beam computed tomography (CT) scan obtained immediately after TACE shows dense iodized oil accumulation in the tumor (arrow). The anterolateral tumor aspect was not completely covered by parenchymal iodized oil deposition (arrowheads), which was classified as grade B. (D) Unenhanced CT scan obtained 1 month after TACE shows dense iodized oil accumulation in the tumor (arrow). (E) Enhanced MR images obtained 4 months later showed tumor recurred at a site without an adequate safety margin (arrows) (peritumoral recurrence).

the tumor and maximizing the therapeutic effect while reducing the adverse effects. ${ }^{6,19,20}$ Based on histopathology, Sasaki et al." reported that microsatellite lesions were found in $46 \%$ of HCC smaller than $5 \mathrm{~cm}$ and observed in $29 \%$ of HCC smaller than $2.5 \mathrm{~cm}$. As a result, we consider that embolization of the safety margin is important in locoregional treatments such as TACE and RFA. The safety margin around a tumor that has microsatellite lesions has been controlled by RFA. However, the local tumor control of TACE is still undesirable compared with local ablative therapy. ${ }^{10,11}$

Our study demonstrated a relationship between the grade of iodized oil deposition with a safety margin and LTR of patients with HCC who underwent superselective TACE. LTR was significantly lower in tumors with complete circumferential safety margin (11\%) on CBCT images compared with tumors without or an incomplete circumferential safety margin (43\%). In other words, tumors with circumferential safety margin during superselective TACE predicts low LTR. These findings suggest that the safety margin of iodized oil during TACE also affects microsatellite lesions around the tumor, which results in a lower rate of LTR. The results of our study are similar to a previous study, ${ }^{21}$ that demonstrated sufficient safety margin can significantly reduce LTR $29 \%$ in the complete safety margin group versus $67 \%$ in the incomplete safety margin group). However, there are some differences in the terms of the methodology. In a previous study, ${ }^{21}$ the minimal safety margin was defined as $5 \mathrm{~mm}$ wide for a tumor $<25 \mathrm{~mm}$ and at least 10 $\mathrm{mm}$ wide for a tumor $\geq 25 \mathrm{~mm}$ on $\mathrm{CT}$ images one week after the TACE procedure. In our study, CBCT images were performed immediately after TACE to evaluate the iodized oil deposition and safety margin. Although the signal to noise ratio is lower compared with multidetector $\mathrm{CT}$, the availability of $\mathrm{CBCT}$ images in 

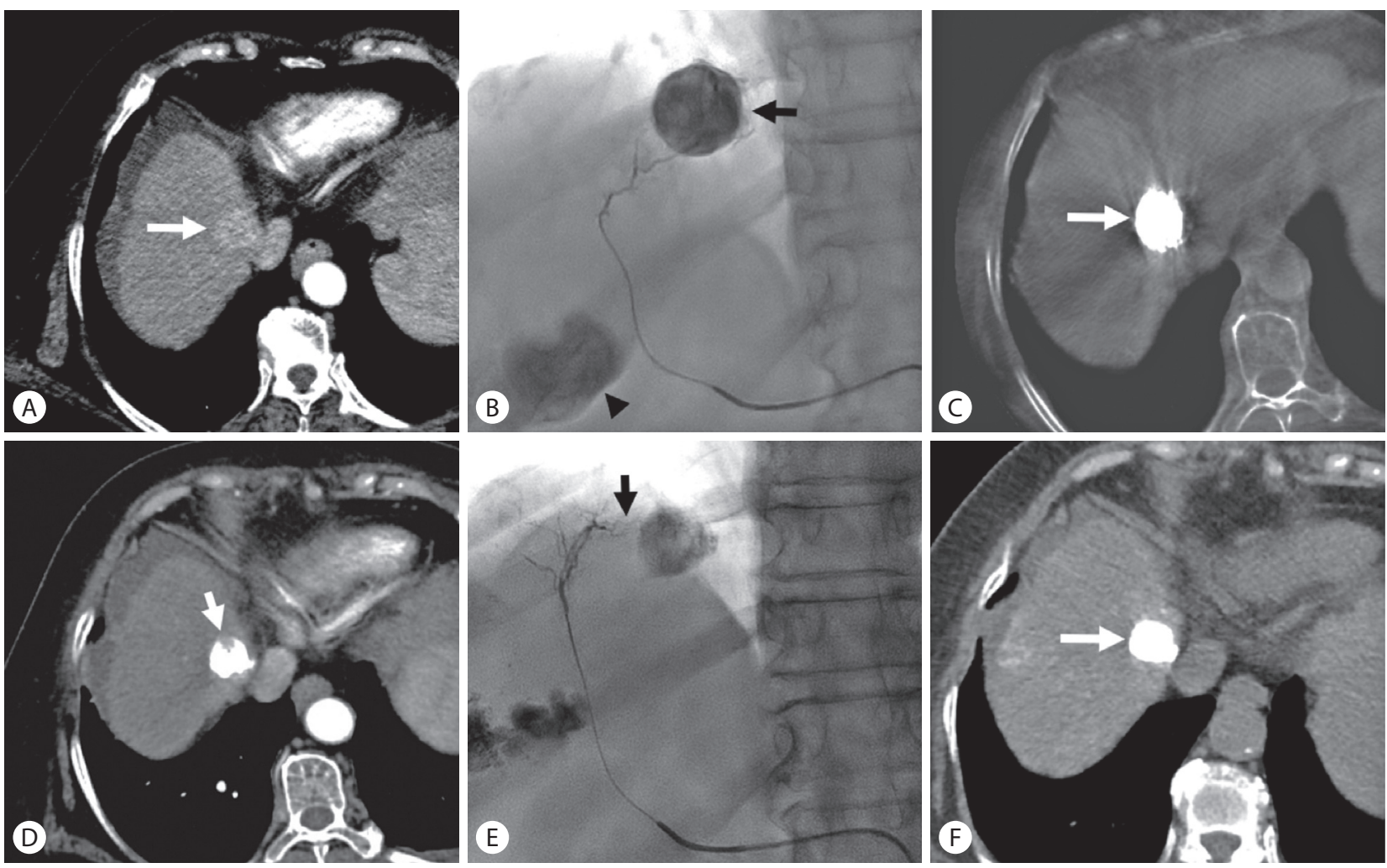

Figure 5. Local tumor recurrence after transarterial chemoembolization (TACE) in a 72-year-old woman with hepatocellular carcinoma. (A) Enhanced computed tomography (CT) scan shows a 2.6-cm-sized hypervascular nodule at segment 8 of the right hepatic lobe (arrow). (B) Superselective TACE was performed at the anterior superior segmental artery of the right hepatic artery until complete tumor staining (arrow). The arrowhead indicate another tumor staining. (C) Cone-beam CT scan obtained immediately after TACE shows dense iodized oil accumulation in the tumor (arrow). (D) Enhanced CT scan obtained 1 month after TACE shows a defect of iodized oil accumulation in the tumor (arrow) (intratumoral recurrence). (E) Another branch of the anterior superior segmental artery of the right hepatic artery (arrow) was selected, and a second TACE was performed. (F) Unenhanced CT scan obtained 1.5 months after the second TACE shows dense iodized oil accumulation in the tumor (arrow) without any defect.

the angiography suite allows higher efficacy for targeting of the tumor, locating the tumor feeding artery, and evaluating the safety margin after superselective TACE.

Peritumoral recurrence may represent residual minute tumor growth adjacent to the parent tumor mass that may not be completely embolized during TACE. A total of $10(77 \%)$ of the $13 \mathrm{HCC}$ nodules in the grade B groups (without or incomplete circumferential safety margin) had tumor recurrence at the peritumoral region which was contrary with grade A group (complete circumferential safety margin) that had only $1(14 \%)$ in 7 nodules of peritumoral recurrence. In other words, most cases of peritumoral recurrence were found in HCC tumors with inadequate safety margin. These findings also suggest that a safety margin after superselective TACE is important. However, achieving a circumferential safety margin requires additional embolization of the hepatic artery that supplies the liver parenchyma surrounding the tumor nodule. This would cause decrease of hepatic functions in HCC patients with borderline or poor liver function when the embolization area is large. Therefore, the size of the TACE area and hepatic function reserve of the patient need to be considered.

In grade C group, all residual or recurrent nodules occurred at the intratumoral region. All cases were seen in nodules with defective iodized oil uptake on CBCT images. This was possibly related to technical issues, such as incomplete embolization of the feeding artery or missing some small feeding branches during chemoembolization. In superselective TACE, catheterization into the distal subsegmental artery may increase the risk of missing a small feeding artery arising proximately to the microcatheter tip which may lead to incomplete embolization of the tumor. ${ }^{\text {? }}$

Our study determined that prominent portal vein visualization at spot digital radiography is an independent prognostic factor for a lower LTR rate, which was a result that was similar to a previous study by Miyayama et al. ${ }^{7}$ For the same reason, a markedly demonstrated portal vein during superselective TACE may suggest ad- 
unresectable hepatocellular carcinoma. Hepatology 2002;35:11641171.

5. Llovet JM, Real MI, Montaña X, Planas R, Coll S, Aponte J, et al. Arterial embolisation or chemoembolisation versus symptomatic treatment in patients with unresectable hepatocellular carcinoma: a randomised controlled trial. Lancet 2002;359:1734-1739.

6. Matsui O, Kadoya M, Yoshikawa J, Gabata T, Arai K, Demachi H, et al. Small hepatocellular carcinoma: treatment with subsegmental transcatheter arterial embolization. Radiology 1993;188:79-83.

7. Miyayama S, Matsui O, Yamashiro M, Ryu Y, Kaito K, Ozaki K, et al. Ultraselective transcatheter arterial chemoembolization with a $2-f$ tip microcatheter for small hepatocellular carcinomas: relationship between local tumor recurrence and visualization of the portal vein with iodized oil. J Vasc Interv Radiol 2007;18:365-376.

8. Iwamoto S, Yamaguchi T, Hongo O, Iwamoto H, Sanefuji H. Excellent outcomes with angiographic subsegmentectomy in the treatment of typical hepatocellular carcinoma: a retrospective study of local recurrence and long-term survival rates in 120 patients with hepatocellular carcinoma. Cancer 2010;116:393-399.

9. Bronowicki JP, Vetter D, Dumas F, Boudjema K, Bader R, Weiss AM, et al. Transcatheter oily chemoembolization for hepatocellular carcinoma. A 4-year study of 127 French patients. Cancer 1994;74:1624.

10. Kim KW, Lee JM, Klotz E, Kim SJ, Kim SH, Kim JY, et al. Safety margin assessment after radiofrequency ablation of the liver using registration of preprocedure and postprocedure CT images. AJR Am J Roentgenol 2011;196:W565-W572.

11. Sasaki A, Kai S, Iwashita Y, Hirano S, Ohta M, Kitano S. Microsatellite distribution and indication for locoregional therapy in small hepatocellular carcinoma. Cancer 2005;103:299-306.

12. Pung L, Ahmad M, Mueller K, Rosenberg J, Stave C, Hwang GL, et al. The role of cone-beam $\mathrm{CT}$ in transcatheter arterial chemoembolization for hepatocellular carcinoma: a systematic review and metaanalysis. J Vasc Interv Radiol 2017;28:334-341.

13. Deschamps F, Solomon SB, Thornton RH, Rao P, Hakime A, Kuoch V, et al. Computed analysis of three-dimensional cone-beam computed tomography angiography for determination of tumor-feeding vessels during chemoembolization of liver tumor: a pilot study. Cardiovasc Intervent Radiol 2010;33:1235-1242.
14. Miyayama S, Yamashiro M, Hashimoto M, Hashimoto N, Ikuno M, Okumura $\mathrm{K}$, et al. Identification of small hepatocellular carcinoma and tumor-feeding branches with cone-beam CT guidance technology during transcatheter arterial chemoembolization. J Vasc Interv Radiol 2013;24:501-508.

15. Iwazawa J, Ohue S, Hashimoto N, Muramoto O, Mitani T. Clinical utility and limitations of tumor-feeder detection software for liver cancer embolization. Eur J Radiol 2013;82:1665-1671.

16. Bruix J, Sherman M; American Association for the Study of Liver Diseases. Management of hepatocellular carcinoma: an update. Hepatology 2011;53:1020-1022.

17. Brown DB, Cardella JF, Sacks D, Goldberg SN, Gervais DA, Rajan DK, et al. Quality improvement guidelines for transhepatic arterial chemoembolization, embolization, and chemotherapeutic infusion for hepatic malignancy. J Vasc Interv Radiol 2009;20(7 Suppl):S219 S226.e1-10.

18. Yamada R, Sato M, Kawabata M, Nakatsuka H, Nakamura K, Takashima S. Hepatic artery embolization in 120 patients with unresectable hepatoma. Radiology 1983;148:397-401.

19. Uchida H, Ohishi H, Matsuo N, Nishimine K, Ohue S, Nishimura Y, et al. Transcatheter hepatic segmental arterial embolization using lipiodol mixed with an anticancer drug and gelfoam particles for hepatocellular carcinoma. Cardiovasc Intervent Radiol 1990;13:140145.

20. Bannangkoon K, Hongsakul K, Tubtawee T, Mc Neil E, Sriplung H, Chongsuvivatwong $V$. Rate and predictive factors for sustained complete response after selective transarterial chemoembolization (TACE) in patients with hepatocellular carcinoma. Asian Pac J Cancer Prev 2018;19:3545-3550.

21. Miyayama S, Yamashiro M, Hashimoto M, Hashimoto N, Ikuno M, Okumura $\mathrm{K}$, et al. Comparison of local control in transcatheter arterial chemoembolization of hepatocellular carcinoma $\leq 6 \mathrm{~cm}$ with or without intraprocedural monitoring of the embolized area using cone-beam computed tomography. Cardiovasc Intervent Radiol 2014;37:388-395.

22. Goseki N, Nosaka T, Endo M, Koike M. Nourishment of hepatocellular carcinoma cells through the portal blood flow with and without transcatheter arterial embolization. Cancer 1995;76:736-742. 